\title{
Exercer a Postura Crítica: Desafios no Estágio em Psicologia Escolar
}

\author{
Exercising Critical Stance: Challenges in a School \\ Psychology Internship
}

Ejercer la Postura Crítica: Desafíos en el Contrato de Prácticas en Psicología Escolar

Adriana Marcondes Machado

Universidade de São Paulo

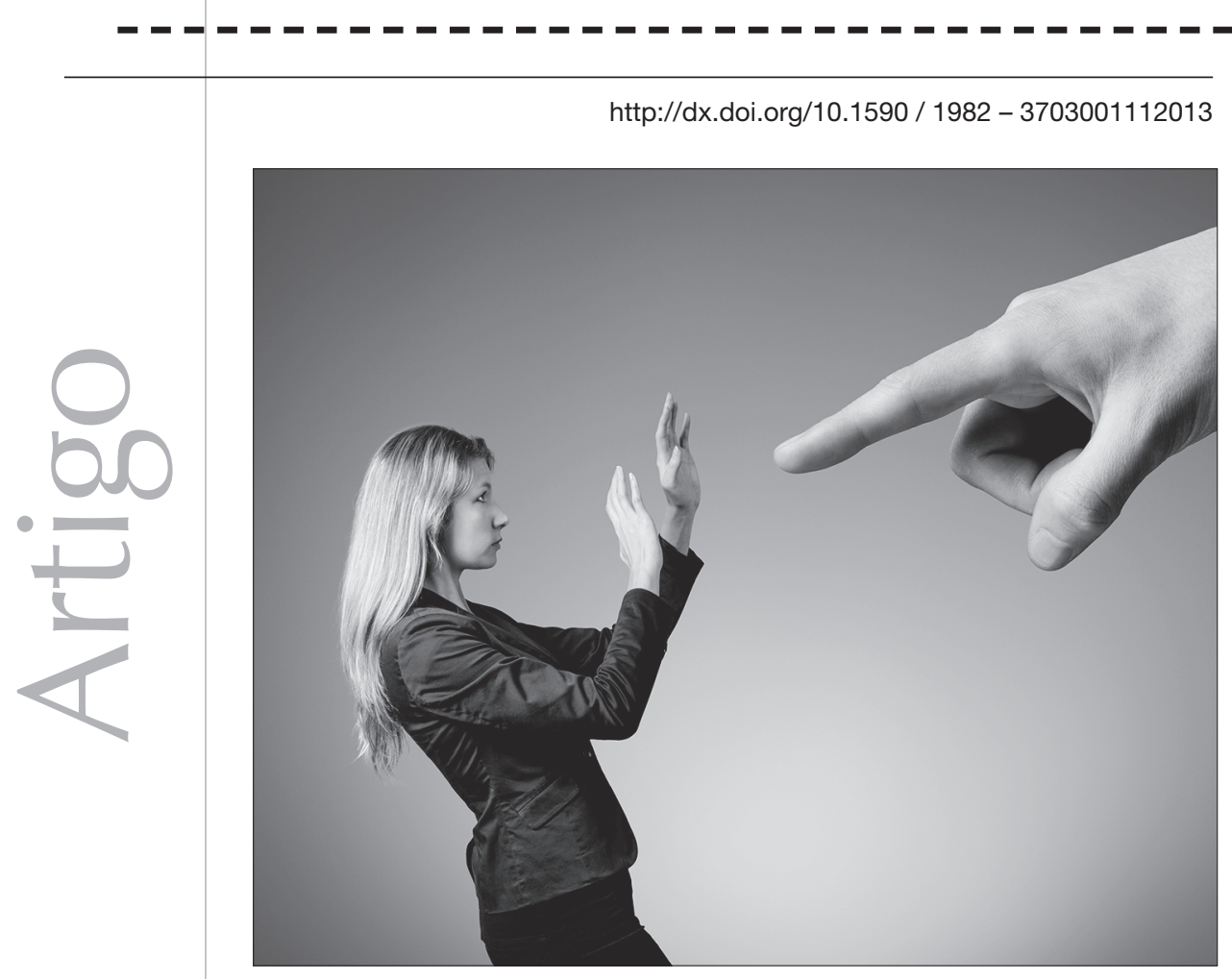


Resumo: Os estudantes de graduação do curso de Psicologia do Instituto de Psicologia da Universidade de São Paulo, ao cursarem as disciplinas relacionadas à área da Psicologia Escolar, realizam estágios em instituições educativas. Imbuídos de uma postura crítica, os estagiários entram em contato com demandas de tratamento, prevenção e adaptação e compreendem a produção histórica destas. Todavia, em muitos momentos, os estagiários julgam essas demandas como se fossem equivocadas e, dessa forma, não conseguem perceber a multiplicidade de elementos que as constituem e as formas para agir em sua produção. O objetivo deste artigo é apresentar um percurso de trabalho enfatizando as estratégias criadas para dar conta de um dos desafios que se apresentam no grupo de supervisão: intervir nesse momento no qual os estagiários consideram o funcionamento da escola como algo exterior a eles. As estratégias criadas indicam que a desconstrução necessária na formação dos estudantes de Psicologia para que aprendam a intervir nos processos institucionais vividos durante os estágios requer, também, a desconstrução de uma forma de pensar que cria um suposto sujeito fora do diagrama de forças em que o processo do estágio faz parte.

Palavras-chave: Formação do psicólogo. Psicologia Escolar. Estudantes universitários (Psicologia). Relatórios.

Abstract: Undergraduate students of the Psychology Course at the Institute of Psychology of the University of São Paulo, perform internships in educational institutions when attending the disciplines related to the area of School Psychology. Imbued with a critical stance interns face demands for treatment, prevention and adaptation, and they comprehend the historical production of these demands. But in many cases, interns believe these claims are wrong, and thus fail to realize the multiplicity of elements that constitutes them and the forms and to act in its production. The objective of this paper is to present a course of study emphasizing the strategies developed to work with one of the challenges that present themselves during the supervision: to intervene at that point in which interns consider the school as something foreign to themselves. The strategies developed indicate that the deconstruction needed in the training of psychology students to learn to intervene in institutional processes experienced during the internships also requires the deconstruction of a way of thinking that creates a pretended subject who is outside the force diagram in which the intern process is.

Keywords: Training Psychologist. School Psychology. College students (Psychology). Reports.

Resumen: Los estudiantes de pregrado del Curso de Psicología del Instituto de Psicología de la Universidad de São Paulo al asistir a los cursos relacionados al área de Psicología Escolar realizan prácticas pre-profesionales en instituciones educativas. Imbuidos de una postura crítica los practicantes entran en contacto con demandas de tratamiento, prevención y adaptación, y comprenden su producción histórica. Sin embargo, en muchos momentos los practicantes juzgan esas demandas como si fueran equivocadas $y$, por tanto, no consiguen percibir la multiplicidad de elementos que las constituyen y las formas de actuar en su producción. El objetivo de este artículo es presentar el recorrido de un trabajo que enfatiza las estrategias creadas para atender a uno de los retos que se presentan en el grupo de supervisión: realizar intervención en el momento en el que los practicantes consideran el funcionamiento de la escuela como algo exterior a ellos. Las estrategias creadas señalan que la desconstrucción necesaria en la formación de los estudiantes de psicología para que aprendan a intervenir en procesos institucionales vividos durante las prácticas requiere también la desconstrucción de una forma de pensar que crea un supuesto sujeto fuera del diagrama de fuerzas en el que el proceso de prácticas participa.

Palabras-clave: Formación del psicólogo. Psicología-escolar. Estudiantes universitarios (Psicología). Informes. 


\section{O problema: como exercer a postura crítica}

Quando os estudantes do curso de graduação em Psicologia do Instituto de Psicologia da Universidade de São Paulo (IPUSP) iniciam os estágios das disciplinas da área da Psicologia Escolar, contam-nos que sabem o que não é para fazer, sabem que existem práticas que discriminam e rotulam, sabem que existem ações que reduzem os sujeitos a índices e números, sabem sobre o perigo de interpretações totalitárias, sabem que a Psicologia e os psicólogos reproduzem relações de desigualdade de poder, sabem do perigo presente nos encaminhamentos de alunos das escolas para avaliação psicológica quando estes isentam o funcionamento social e institucional da responsabilidade pela produção de fracasso escolar, e perguntam: como agir diferentemente disso? Como exercer a postura crítica? Até esse momento do curso, os alunos de Psicologia estudaram a relação entre o funcionamento do sistema capitalista e as produções do fracasso escolar e da intensa desigualdade em nosso país (Patto, 1984, 1990; Chauí, 1980; Tanamachi, Proença \& Rocha, 2000; Machado, 2003). Esses estudantes cursam o $7^{\circ}$ semestre do curso de Psicologia (a graduação em Psicologia tem 10 semestres) e suas indagações revelam que teria sido muito importante que as atividades de extensão pudessem estar mais presentes desde o início da graduação.

Ao chegarem às escolas públicas, onde alguns dos estágios são realizados, estão abertos, disponíveis e curiosos para entender os acontecimentos que lá acontecem. As primeiras idas à instituição escolar são, normalmente, impactantes. Experimentam situações difíceis e uma das reações é crerem que deveria haver mudança de atitude por parte dos professores que trabalham nas escolas. Muitas vezes defendem que os professores poderiam agir de uma maneira mais crítica se não individualizassem as causas da produção do fracasso escolar dos alunos com os quais se preocupam. Nas primeiras supervisões do estágio, uma das hipóteses que os estudantes de Psicologia formulam é de que seria necessário apresentar aos professores das escolas considerações que os ajudassem a perceber a responsabilidade deles na produção daquilo que é tomado como problema. Com isso, os estagiários têm esperança de que os professores mudem suas atitudes.

Essa situação nos mostra uma questão que se revela fundamental para ser trabalhada durante o estágio: uma posição dos estudantes de Psicologia segundo a qual o outro é considerado equivocado (como se o problema estivesse na ação do professor). Pensando dessa forma, os estagiários sugerem que deveriam explicitar ao professor aquilo que está acontecendo e que não está sendo percebido para, assim, produzir mudanças nos gestos. Essa posição dos estudantes de Psicologia é um dos desafios para a supervisão, pois eles tratam os professores das escolas públicas de uma maneira muito parecida com a que, muitas vezes, os professores dessas escolas tratam seus alunos.

O objetivo deste artigo é apresentar um percurso de trabalho enfatizando a busca de estratégias para dar conta de um dos desafios que se apresentam nos grupos de supervisão: intervir nesse momento no qual os estagiários consideram o funcionamento da escola como algo exterior a eles. Portanto, esse trabalho faz parte de uma investigação sobre os problemas e desafios que se operam na formação de alunos do curso de Psicologia. Para isso, discutiremos a forma como os estagiários de Psicologia têm analisado os problemas produzidos no espaço escolar e apresentaremos as estratégias criadas para problematizar essas análises utilizando relatórios escritos pelos estagiários durante a experiência de estágio e reflexões realizadas nas supervisões.

Essa busca de estratégias requer o entendimento de que a intervenção e a investigação caminham juntas. Para isso, temos como subsídio os aportes teóricos da pesquisa-intervenção (Aguiar \& Rocha, 2007; Altoé, 2004), em que o profissional está envolvido no próprio diagrama de forças que investiga, buscando formas de agir naquilo que se constitui nesse campo. Para apresentarmos o desafio nesse momento da formação dos estudantes de Psicologia, focalizaremos o formato do trabalho e os diferentes tempos 
vividos em estágios realizados durante os anos de 2009, 2010 e 2011 em Escolas Públicas Municipais da cidade de São Paulo.

\section{Formato do trabalho: entre a universidade e o campo de estágio}

No curso de Psicologia do IPUSP, temos três disciplinas que se articulam formando uma sequência de discussões da área de Psicologia Escolar. Duas são obrigatórias, teóricas, e ministradas no quinto e sexto semestres do curso. A terceira disciplina é optativa e ministrada no sétimo semestre. Os estágios são realizados nessa disciplina optativa, na qual trabalham uma docente e três psicólogas do Serviço de Psicologia Escolar. As psicólogas estabelecem as relações com as escolas públicas e outras instituições de caráter educativo para organização dos estágios. Os estudantes de Psicologia que se inscrevem nessa disciplina optativa são divididos em grupos - seis a oito estudantes por grupo de supervisão, que trabalharão em duplas. Cada grupo cumprirá duas horas semanais de supervisão, duas horas semanais de estágio na instituição, duas horas semanais de aula teórica e tempo para escrita de relatórios semanais com descrição e análise dos acontecimentos vividos no estágio.

Cada uma das três psicólogas do Serviço de Psicologia Escolar do IPUSP tem a responsabilidade de supervisionar os estágios de intervenção desses grupos de estagiários. Essa informação é fundamental, pois entendemos que as estratégias que desenvolvemos foram fruto da possibilidade de um contrato de trabalho (como psicólogo do IPUSP) no qual a função de extensão da Universidade é priorizada e aprimorada. Sabemos que a maioria das instituições de ensino superior não tem equipes de trabalho (docentes e psicólogos) para formularem e organizarem os estágios dos alunos. As estratégias investigadas e experimentadas durante o trabalho de supervisão a serem aqui apresentadas vêm sendo gestadas há tempos e a organização atual é fruto de muitos movimentos (Machado, 2003; Machado \& Souza, 1997).
Muitos estágios são realizados em escolas municipais de ensino infantil e de ensino fundamental. As dificuldades são narradas pelos estagiários com muita angústia. Quando vamos às escolas públicas, os professores nos pedem que ajudemos em situações muito difíceis, urgentes, que precisam de intervenções imediatas. Fomos aprendendo a demarcar diferentes tempos vividos no estágio e a intensificar formas de trabalhar esses tempos com os estagiários de Psicologia. Durante os quatro meses de trabalho, os estagiários vão, em média, 15 vezes às escolas e, como descrevemos acima, têm supervisões semanais. Tudo muito intenso e rápido.

Cada dupla de estagiários se compromete a estar na escola duas horas por semana e é responsável por trabalhar com uma situação escolar durante o estágio que, como veremos, nos remete a vários temas que atravessam o cotidiano escolar. Muitas vezes, essas situações que farão parte do trabalho de estágio foram definidas antes de ele se iniciar, nos encontros que o psicólogo supervisor teve com os profissionais que trabalham na escola. Comumente, essas situações estão relacionadas a histórias singulares: uma certa aluna tem comprometimentos orgânicos, está no 6 ㅇan ano (antiga $5^{a}$ série, isto é, primeiro ano do Ensino Fundamental II) e tem apresentado muitas atitudes agressivas que não eram comuns no ano anterior quando ainda frequentava o Ensino Fundamental I; um outro aluno apresenta dificuldades intensas e se recusa a fazer as coisas que Ihe pedem; uma sala de aula do 3o ano vive muitas cenas de indisciplina. As situações começam a aparecer dessa forma, por aquilo que inquieta, que preocupa, que tensiona. Sabemos que esses acontecimentos (como todo acontecimento) são efeitos de relações que precisarão ser habitadas e conhecidas para que o trabalho se realize.

\section{Relatos semanais: entre o campo de estágio e a supervisão}

Os estagiários escrevem, semanalmente, para a supervisão, relatos sobre o que ocorreu no estágio, contendo fatos e análises. Esses escritos são denominados "relatos se- 
manais" e são lidos pelo supervisor (e, se possível, pelos outros estagiários do grupo) antes da supervisão. Pedimos que os estagiários os enviem mesmo se o estágio for realizado um dia antes da supervisão. Por exemplo, uma dupla que realizava o estágio na segunda-feira e a supervisão era na terçafeira de manhã, enviava os relatos semanais até segunda-feira, às 21 horas, para que fossem lidos no dia seguinte bem cedo. Enfatizamos esse procedimento, pois tem sido importante para aproveitarmos o tempo da supervisão, termos acesso a esse material escrito antes que os estagiários nos contem sobre os acontecimentos no estágio. É comum que situações muito mobilizadoras demandem tempo da supervisão para serem narradas e pensadas. Sabemos da importância dessas narrativas, mas ao termos as informações escritas nos relatos semanais, agilizamos a ampliação do campo de análise daquilo que está sendo apresentado pelo estagiário, sem ficarmos aprisionados nas sensações e opiniões. Por exemplo, um dia uma estagiária havia escrito em seu relato semanal uma situação bastante tensa que havia ocorrido entre a professora do $3^{\circ}$ ano e os alunos. Havia sumido os estojos de duas alunas e a professora avisou que, se os estojos não fossem devolvidos, todos seriam revistados antes de irem para casa. Os alunos foram para o recreio e, durante esse tempo, a professora e o coordenador tiveram uma conversa da qual a estagiária também participou e, nela, decidiram que haveria outro procedimento, e os alunos não seriam revistados. No relato semanal, a estagiária havia narrado mudanças na postura da professora após essa conversa, mas ao contar sobre esse fato na supervisão, ela se deteve bastante tempo na cena em que a professora havia feito a ameaça, pois tinha ficado muito aflita quanto à possibilidade de inspeção. Sabendo das mudanças ocorridas na postura da professora, foi possível ouvir a indignação da estagiária, considerando que ela estava narrando uma situação com movimento: a professora buscou o coordenador para conversar durante o recreio e mudou de ideia, conversando com seus alunos de outra forma. A possibilidade de ter um coordenador para conversar naquele momento nos indica que o gesto da professora está articulado a um campo complexo e que faz diferença uma escola em que há tempo e pessoas para pensarem as situações do dia a dia. A conversa com o coordenador foi fundamental para analisar melhor a situação. Portanto, pensar que os alunos deveriam ser revistados ou que seria importante outro tipo de intervenção, dependerá de um campo de relações, de uma multiplicidade de acontecimentos e funcionamentos institucionais.

As sensações e interpretações dos estagiários nos servem como alavanca para conhecermos o campo de relações. A supervisão também faz parte desse campo, isto é, o que se relata, como se relata e o que se analisa não são fatos apenas exteriores à supervisão, mas também produzidos nela. O julgamento negativo feito pela estagiária perante o gesto inicial da professora revela indignação e interpreta a atitude da professora como equivocada. Insistimos nessa diferença: indignar-se e interpretar o outro como equivocado são direções diferentes. Podemos discordar do gesto da professora, ficarmos indignados, mas ele é constituído historicamente, assim como nossos pensamentos. Não é um equívoco. Concluir a análise de um acontecimento com julgamentos negativos em relação aos gestos dos outros é um pensamento reducionista que nos dá a ilusão de estarmos fora do campo de relações, como se não estivéssemos produzindo aquilo que analisamos, como se sempre houvesse algo anterior às relações. No entanto, cada acontecimento é efeito de um complexo campo de forças, e nossas ideias não apenas falam desse campo, elas o constituem, são forças. Essa potência de criação, de constituir força, precisará ser intensificada (Passos, Kastrup, \& Escóssia, 2009), agenciada, durante o estágio.

Portanto, o relato semanal serve de apoio para a supervisão. Fomos percebendo que esses relatos semanais não apenas informavam o percurso e os movimentos no estágio, mas também a forma como os estagiários pensavam os acontecimentos. Apresentaremos, a seguir, os diferentes momentos do estágio: primeira visita, definição de um território disparador, cartas-relatórios, ampliação do campo de análise, tempos de fechamento. 


\section{A primeira ida dos estagiários à instituição: entre o contrato e o recontrato do trabalho}

No primeiro dia de supervisão, são apresentadas informações aos estagiários sobre a relação estabelecida com a escola e trazidos alguns temas que foram indicados pelos professores. Em algumas experiências, esses temas são definidos em uma reunião na escola em que os estagiários também estão presentes. Logo na primeira supervisão, o supervisor organiza uma tabela com os horários de estágio de cada dupla na instituição e, também, horários extras em comum por dupla, caso sejam necessários. Essa tabela é fundamental para que todos saibam dos horários das duplas, pois o que acontece com uma dupla de estagiários terá efeitos no trabalho das outras duplas.

Definidos o dia e o horário em que cada dupla de estagiário estará na escola, essa questão (cumprir tempos e ocupar espaços) será fundamental. Entregamos para a escola uma planilha com o nome de todos os estagiários e os horários em que estarão na escola e, depois, acrescentamos os temas com que irão trabalhar. Também entregamos, por escrito, nosso objetivo com o estágio.

É importante que os estagiários comecem o trabalho nas instituições rapidamente. Logo depois da primeira supervisão, eles vão à escola. Às vezes, o supervisor acompanha o grupo de estagiários na visita inicial, mas, na maioria das vezes, eles vão para a escola sem o supervisor, apresentam-se para a equipe de coordenação da escola e procuram o professor com o qual trabalharão alguma situação. Até esse momento, tudo dependeu muito da relação entre o supervisor e o grupo de professores da escola. Quando os estagiários vão à escola e se apresentam aos professores com os quais vão trabalhar, ocorrem mudanças na forma de as questões serem colocadas. É comum os professores relatarem para os estagiários, de outras maneiras, com outras intensidades, aquilo que haviam narrado na reunião de professores. Por exemplo, a professora que havia contado sobre uma sala do $3^{\circ}$ ano muito indisciplinada comentou com os estagiários o incômodo que ela sentia naquela escola, pois gostava do trabalho que exercia na escola em que trabalhava anteriormente, mas, como tinha um contrato de trabalho precário, perdeu sua vaga para outra professora que era efetiva na Secretaria de Educação. Entendemos que, a partir das relações que os estagiários estabelecem com os profissionais da instituição, ocorre um recontrato do trabalho. Recontrato no sentido de que, agora, os estagiários e a professora com quem trabalharão definirão preocupações, temas e ações (que antes eram definidos entre o supervisor e os educadores). Os estagiários aprenderão a criar um campo comum de trabalho com as professoras, precisarão conhecer as expectativas e as preocupações das pessoas com as quais trabalharão.

Logo no início, os estagiários percebem que o fato de serem da área da Psicologia intensifica a produção de queixas e a busca por explicações individualizadas. Também há professores que parecem se desculpar aos estagiários todas as vezes em que precisam ser firmes com os alunos. A professora do 3 으 ano repreendeu um aluno e logo disse para a estagiária que sabia que psicólogos não eram a favor de broncas, mas que era necessário agir dessa forma. Portanto, logo no primeiro dia de estágio, essa professora nos indicou uma questão bastante importante: o cuidado que temos que ter devido a estabelecermos relações nas quais parece que nós, psicólogos, somos detentores da boa forma de agir.

Em uma primeira conversa, essa professora havia comentado sobre sala de aula como um todo e, quando os estagiários perguntaram para quais questões e situações seria importante eles estarem atentos, ela falou de três alunos em relação aos quais tinha muita dificuldade para ensinar. Os nomes desses alunos não haviam sido citados até então. Outra professora, que trabalhava com alunos com deficiências em salas de aula específicas (eles estudavam durante a manhã em salas regulares e, durante a tarde, eram divididos em pequenos grupos para terem aula com uma 
professora contratada para ensinar alunos vinculados à educação inclusiva), ressaltou para os estagiários a importância de eles participarem das salas regulares para terem acesso a como esses alunos estavam se desenvolvendo nessas salas.

As informações e os pedidos que os professores fazem aos estagiários são fundamentais e nos dão pistas de como nossos corpos habitam e constituem o campo de forças e relações. Esse aprendizado - perceber-se produzindo aquilo que acontece e criar formas de derivar - é um dos objetivos do estágio.

\section{Território disparador: informa- ções, pedidos, aproximações}

Definidos tempos, espaços e temas, cada dupla de estagiário ocupará um território que chamaremos de território disparador e, também, começará uma relação com algum profissional da escola. Esse território disparador é, na maioria das vezes, a sala de aula (quando o estágio ocorre em Casas Abrigo, é a sala, a cozinha ou o quintal). Os estagiários frequentarão esse território durante três ou quatro semanas. Uma palavra se repete bastante nas primeiras semanas de supervisão: aliança.

Criar aliança com os professores implica algo mais do que entender a história que constitui certo tipo de demanda. Implica percebermos isso - a produção da demanda - se operando na relação que estabelecemos com os educadores. Quando um grupo de professores em uma escola recusa algum tipo de trabalho que os psicólogos estão oferecendo, temos que concordar com o fato de que aquilo que foi ofertado não estabeleceu nada em comum com os professores. Isto é, eles entenderam que aquilo que explicitaram como necessidade não foi escutado. Uma professora nos contou graves problemas familiares pelos quais passava um aluno seu, com muitas dificuldades para aprender. A forma de relatar, bastante indignada, culpabilizava a família por muitas questões e foi sugerido que, durante o estágio, entrássemos em contato com a família. Se, para um professor, é importante que tenhamos contato com a família, é necessário considerarmos que o pedido nos indica uma abertura a várias questões: para que serviria esse contato com a família, como realizar um bom encontro, o que já foi vivido em relação a essa família? Um exemplo relacionado a esse tema: a coordenadora de uma escola de ensino infantil trouxe a necessidade de falarmos com a mãe de um aluno porque ele tinha apresentado dificuldades na fala que poderiam ser trabalhadas por um(a) fonoaudiólogo(a), mas a mãe não levava o filho ao especialista. Segunda a coordenadora, isso estava dificultando o processo de alfabetização desse aluno. Havia uma indisposição com relação a essa mãe devido a situações anteriores. Conversamos muito sobre qual seria o objetivo desse encontro. Havia a ideia de que, por sermos psicólogos, poderíamos ter mais condições de desmontar o que a fazia resistir e convencê-la de alguma maneira. Convencer? A questão que se colocava é que nem essa mãe afetava a forma como as professoras entendiam e sentiam os fatos, nem as professoras afetavam o que essa mãe vivia. Depois de definido que seria interessante entender melhor como a mãe estava pensando, a conversa foi realizada. Participaram dela: a coordenadora pedagógica, uma das estagiárias de Psicologia e a mãe do aluno. Nessa conversa, a coordenadora contou, novamente, sobre algumas dificuldades que estavam acontecendo na escola e a mãe falou dos entraves que inviabilizavam o atendimento fonoaudiológico (alguns deles conhecemos muito bem: problemas de tempo e vaga para ser atendido, custo de transporte e outros). Conhecer, indagar e pensar promovem direções diferentes do que orientar e cobrar. Surgiram as dificuldades em se priorizar esse atendimento em uma vida na qual tantas dores não estão podendo ser atendidas. A coordenadora precisaria intervir nos encaminhamentos de alunos que a escola fazia para a Unidade Básica de Saúde. Isso demandava telefonemas, encontros, conversas, criação de redes e discussões. Nada fácil. A sensação dos educadores de que essa mãe, em especial, não se esforçava por conseguir o que era necessário para o filho era presente. Nossa preocupação era com a rápida conexão que se fazia entre essa sensação e a ideia de que essa mãe era, em sua essência, alguém displicente. 
Aceitar ou recusar uma demanda impede que ela sirva para analisar a situação e, com isso, torna-se difícil desconstruir e dar visibilidade ao campo de forças no qual foi constituída. A demanda permite a imersão no campo, abre o campo. Ela é formulada aos estagiários de Psicologia e, ao mesmo tempo, a Psicologia se constitui, historicamente, na existência dessas demandas.

Portanto, criar alianças e perguntas para conhecer as situações com as quais trabalharão, já estará acontecendo no primeiro dia de estágio. As informações precisam ser registradas nos relatos semanais, por exemplo: o incômodo da professora em relação à escola atual (Quais diferenças entre a escola atual e a anterior? Como tem sido processada a discussão sobre atribuição de salas para professores?); o fato de uma certa professora achar que psicólogos não gostam de broncas (Quando são necessárias? Quando não funcionam?); a necessidade de acompanhar os alunos com deficiências nas salas regulares (Quais hipóteses temos para esse pedido? Quais são as preocupações da professora da educação inclusiva?). Essas são algumas perguntas que surgiram logo no primeiro dia de estágio. Durante algumas poucas semanas - cerca de três -, os estagiários frequentam esses territórios disparadores e as dúvidas formuladas servirão de norte para suas ações.

\section{Escrita ato: as cartas-relatórios}

Os estagiários ficam indignados, tristes, alguns choram na supervisão. É difícil conviver com tantas histórias de abandono, medo, perdas, humilhação. Entram em contato com situações de vida muito difíceis e percebem a complexidade e a precariedade do funcionamento institucional.

Os relatos semanais, como dissemos, são entregues para o supervisor e para o grupo de supervisão, mas percebemos que eles criavam uma ilusão: parecia que aquilo que estava escrito seria uma descrição, uma explicação exterior que não estaria criando aquilo que estava sendo descrito e explicado. Escreviam sobre alguns acontecimentos na escola sem se colocarem nas disputas e tensões em que estes se constituem. Darei como exemplo um trecho escrito em um dos relatos semanais: "O coordenador da escola se mostra muito indisponível para pensar sobre o processo de aprendizado de Felipe defendendo que a função da escola é, nesses casos, apenas socializar. Dessa forma, a escola não tem ensinado aquilo que ele poderia aprender". Esse texto defendia que Felipe teria maior capacidade para aprender do que era desenvolvido e que o coordenador estava tendo menos disponibilidade do que deveria ter. Uma escrita estagnada, que define a vida por um estado e totaliza as existências.

Percebemos que havia um problema na construção da escrita do relato semanal e que, para intervir nisso, seria necessário criar outro tipo de prática. Nos relatos semanais, os estagiários registram acontecimentos, análises e informações para o supervisor e sobre a escola. Passamos a pedir para que escrevessem cartas-relatórios, que são, desde o início, direcionadas aos profissionais das instituições em que estagiam e, portanto, são para os envolvidos nas situações do estágio. Elas serão entregues aos professores ao final do estágio e, até lá, terão muitas variações antes da versão final, pois, a cada dia de estágio, as análises mudam.

As perguntas que inspiram esses escritos são: Qual a função do estágio de Psicologia na escola (objetivo)? Quais situações vivenciaram (cenas)? O que pensam sobre essas situações (reflexões)? O que propõem (pensamentos e ações)? Cada dupla de estagiários funciona de forma diferente em relação a esse escrito: algumas escrevem juntas, outras duplas optam por um escrever primeiro e depois o outro fazer sugestões; às vezes, escrevem um pouco sobre cada pergunta, outras vezes, desenvolvem muito uma das perguntas e deixam as outras para um momento posterior.

As cartas-relatórios têm sido um exercício importante para os estagiários se perceberem no interior dos fatos: por serem palavras que visam a afetar um campo relacional, a escolha destas exige reflexões sobre os efeitos que produzem. No início, ocorrem muitas generalizações, definições que fecham a 
existência ao colocar as pessoas como sujeitos das frases, sujeitando-as aos acontecimentos ("os professores não têm disposição", "Os alunos não prestam atenção", "a mãe não foi ouvida"). A escolha de palavras e frases que tragam a multiplicidade presente em uma situação exige tempo. Os estagiários relatam as dificuldades para realizar essas escolhas, pois vão percebendo que nenhuma palavra é suficiente. Eles têm de pensar na sequência de frases, no que pretendem dizer antes e depois, na forma como vão desenvolver uma linha argumentativa.

Nesses escritos, acompanhamos as transformações na forma de pensar dos estagiários. No início, ao escreverem sobre a necessidade de os professores mudarem a forma de entender seus alunos, revelam uma forma de compreender o mundo que impede criarem campos comuns, afetarem as existências: ao supervisor, reclamam dos professores (portanto, queixam-se), escrevem que estes deveriam mudar (portanto, orientam), todavia, durante o estágio, vão conseguindo transformar a forma de escrever e a maneira de agir. Vejamos isso em um exemplo.

Um aluno com deficiência, do 6 o ano do Ensino Fundamental, ficava parado, sem fazer nada na sala de aula regular. A professora tinha receio de pedir atividades mais complexas a ele, achava que era constrangedor porque esse aluno apresentava muitas dificuldades. Por isso, pedia tarefas muito simples: pintar um desenho já feito, copiar uma letra etc. A estagiária, percebendo que o aluno estava desanimado (afinal, ele podia mais) e que a professora estava receosa (porque desconhecia as forças dessa criança), perguntou para a professora se haveria algum livro infantil pelo qual esse aluno poderia se interessar. A professora citou alguns livros de literatura infantil que havia na biblioteca e que esse aluno teria, inclusive, condições de ver sozinho, pois eram histórias com imagens, sem escrita. O foco, em uma situação como essa, não é criar estratégias de alfabetização e de interesse, mas intervir naquilo que impede a professora de se aproximar desse aluno (ela nunca havia tido uma experiência de ensinar alunos que requerem mudanças na proposta curricular). A ideia do livro surgiu porque essa estagiária estava à espreita, atenta às possibilidades que ocorriam: um dia ela havia reparado que esse aluno pegou um livro de um colega para folhear. Ficar à espreita, esse é mais um dos aprendizados do estágio. Na carta-relatório, a estagiária escreveu: "Um dia, estava na sala de aula atenta ao que Claudinei fazia. Percebi que ele demonstrou interesse por um livro. Eu tinha receio de, ao comentar sobre o livro, desanimá-lo, pois era comum ele se afastar daquilo que gerasse expectativa nos outros. Cheguei perto dele e, ao invés de perguntar se ele gostaria que eu lesse o livro para ele, perguntei se eu poderia ler junto dele (talvez isso nem fizesse diferença). Ele aceitou, vimos as figuras juntos e fomos apontando coisas interessantes, um para o outro". Nesse trecho, a estagiária explicita seus receios e suas apostas. Reconhece que o interesse de Claudinei em relação ao livro está interligado às expectativas que se criam nas relações. Entende, portanto, que a relação que tem com Claudinei pode gerar efeitos diversos. E ela consegue escrever de uma maneira que passa isso ao leitor (a necessidade de cuidado, de não invadir, de insistir) sem orientações e queixas.

\section{Ampliação do campo de análise: surgem possíveis conexões}

Entre o segundo e terceiro mês de estágio, muitas ações são delimitadas: conversar sobre certo tema com uma professora; visitar a Unidade Básica de Saúde na qual alguns alunos são atendidos (e um, em especial, estava faltando muito na escola); participar da reunião de professores do Ensino Fundamental II para discutir a presença de alunos com deficiências; problematizar sobre como foram escolhidas as crianças que representariam a escola em um evento literário; marcar encontros com as professoras de alguns alunos em relação aos quais os estagiários têm se aproximado; buscar a inspetora de alunos que é vizinha de um aluno que tem faltado etc. Muitas iniciativas e conversas a serem realizadas. Durante esse tempo, é comum que, como supervisoras dos estágios, participemos sistematicamente (quinzenalmente ou a cada três semanas) de reu- 
niões de professores. Em um dos trabalhos em que eu era a supervisora, participava quinzenalmente de reuniões dos professores do período da manhã - Ensino Fundamental I. Em outra escola, eu ia duas vezes por mês nas reuniões, sendo uma na hora do almoço (com professores do Ensino Fundamental I do período da manhã) e outra no final da tarde (com professores do Ensino Fundamental II do período da tarde). Nesses encontros com os professores, discutimos sobre algumas reflexões formuladas durante os estágios. Foi assim que, em uma dessas reuniões, surgiu o assunto dos critérios utilizados na escolha de 10 alunos que poderiam participar de um evento literário. Os estagiários estavam próximos de um aluno que havia dito: "eu nem quero mesmo participar disso aí". Disso o quê? De que falava? Os melhores alunos (por nota e comportamento) eram indicados pelos professores. Pudemos trazer, nessa reunião, as tensões presentes em decisões como essa, enfatizando que a questão não é apenas pensar a melhor forma de escolher (também é, ela engendra processos de subjetivação), mas, além disso, perceber que a revolta da maioria dos alunos por não poder ir ao evento tem relação com o fato de não haver transporte para que todos os alunos de uma certa série pudessem ir. A reação "eu nem queria ir mesmo" exige que consideremos todos esses elementos, pois, do contrário, não entenderemos do que esse menino se defende.

Nesse terceiro mês de estágio, os estagiários já trazem situações para serem discutidas, diferentemente do início, quando pedem orientação sobre o que fazer. Percebem mais claramente as relações de forças que habitam, percebem que são forças nessas relações de forças e que, quanto mais avançam nas interpretações, mais chegam a uma região em que o próprio intérprete desaparece, em que a interpretação e a compreensão produzem aquilo que interpretam e compreendem, como se a interpretação precedesse o símbolo a ser interpretado (Foucault, 1987, 1980/2006).

Os estagiários sabem que podem produzir inflexões importantes conforme o funcionamento desse campo de forças e circulam, falam com pessoas, investigam. Contudo, penso que a maior conquista nesse tempo é a capacidade que desenvolvem de afetar e serem afetados pelos acontecimentos. Vão percebendo estratégias que potencializam aquilo que se apresenta cristalizado. Mas, vejam bem, não é que desenvolvem formas de potencializar os outros, como se faltassem coisas aos outros, mas desenvolvem a capacidade de potencializar as relações que habitam.

Se uma visita a uma Unidade Básica de Saúde torna-se algo importante a ser feito para discussão de uma história singular, isso não pode advir como uma orientação ou sugestão para a escola. A questão não é mostrar ou apontar aos profissionais da escola a importância dessa ação. Criar sentido é uma ação totalmente diferente de verbalizar a necessidade de que algo aconteça. Contagiar é uma ação diferente de orientar. Não que essas ações não carreguem forças em comum, mas não podemos tomar umas pelas outras.

\section{Tempos de fechamento}

As cartas-relatórios prontas têm cerca de quatro páginas. Como dissemos, os estagiários escrevem sobre o objetivo do estágio, as cenas vividas, as reflexões e ações. Muitas vezes, inserem trechos dos relatos semanais e retomam anotações em que pensavam diferentemente do que pensam ao final do trabalho. Buscam escrever movimentos do pensamento. Apresento um exemplo de um trecho de uma carta-relatório sobre o trabalho com um menino de oito anos que, às vezes, ficava nervoso a ponto de bater em quem estivesse perto dele: "Eu não sabia como me aproximar de Diego. Ele tinha acabado de ter uma daquelas crises em que quer bater em todo mundo e estava muito bravo. O inspetor de alunos havia ajudado, impedindo-o de bater nos colegas. Resolvi pegar duas raquetes de pingue-pongue e convidálo a jogar. Sabia que ele gostava desse jogo. Fomos jogar. Depois do jogo perguntei a ele se poderíamos conversar sobre o que tinha acontecido".

Escrever "eu não sabia como me aproximar de Diego. Ele tinha acabado de ter uma daquelas crises em que quer bater em todo 
mundo e estava muito bravo" invoca a necessidade de inventar formas de aproximação e, portanto, as dificuldades e desafios para que a aproximação se desse. Em uma das primeiras versões dessa carta-relatório estava escrito "era difícil se aproximar de Diego, pois ele tinha tido uma crise e estava bravo". Essa forma ressaltava a dificuldade de Diego.

As cartas-relatórios são lidas com as professoras e, dependendo da situação, com o aluno e com os pais. Nessa leitura com as professoras, pedimos que nos indiquem questões que precisam de mudanças na forma de escrever. Não é raro que as professoras apontem trechos em que parece que o estagiário está em uma posição de avaliador sobre o que acontece na escola. Em uma das vezes em que isso aconteceu, no final da carta-relatório estava escrito: "Ficamos muito satisfeitos com as mudanças que puderam se operar na relação entre a professora da sala vinculada à educação inclusiva e a professora da sala regular". A professora nos apontou que essa frase ressaltava a satisfação dos estagiários e não os problemas referentes à concepção e implementação da política de educação inclusiva e as dificuldades enfrentadas no dia a dia para que essas mudanças tivessem ocorrido, como se a satisfação dos estagiários fosse o mais importante.

As cartas-relatórios exigem um trabalho bastante intenso por parte do supervisor e do grupo de alunos e têm substituído, em algumas situações, o relatório final sobre o estágio. Entendemos que os relatos semanais entregues para a supervisão já têm, de maneira suficiente, as informações sobre os fatos e algumas análises sobre o que foi feito. Em vez de sistematizar as informações em um relatório final para o supervisor, compreendemos que essa sistematização deve dialogar com o campo em que o estágio foi realizado, não apenas informando o que foi feito, mas possibilitando que o sentido das ações possa advir, na medida em que os estagiários já conheceram o diagrama de forças e se reconhecem nele. As cartas-relatórios rompem com uma escrita dominada pela representação - uma escrita sobre o outro e força os estagiários a criarem pensamentos e palavras escritas com capacidade conectiva, de contato, de fazer derivar - a escrita para o outro, outro que se constitui, também, com aquilo que se escolhe escrever.

Este trabalho visa a combater uma pesada herança que nos impregna: a filosofia da representação inaugurada por Platão (Fuganti, 2008), que busca a universalidade, o bom modelo, a ideia imutável, a realidade acabada. As interpretações conclusivas dos estudantes de Psicologia no início do estágio revelam essa herança. O desafio explicitado no início do artigo - exercer a crítica - reconhece que a desconstrução necessária na formação dos estudantes de Psicologia para que aprendam a intervir nos processos institucionais vividos durante os estágios requer, também, a desconstrução de uma forma de pensar que cria um suposto sujeito fora do diagrama de forças, que falaria do outro. Os estagiários podem transformar as situações que habitam, ampliando as conexões que possibilitem criar diferenciação em processos cristalizados. A palavra conexão é importante, pois permite visualizar aquilo que Deleuze e Guattari (1972/2010) afirmaram como sendo o desejo - ele é o fluxo, o próprio agenciamento, energia conectiva - e dar relevo à necessidade de criar derivações em situações que entendemos estarem aprisionando a existência. A motivação crítica pretende transformar $\mathrm{o}$ campo social e isso se faz no campo relacional das forças, o que exige aberturas e disposições para criar novas conexões de sentido, de afeto e de maneiras de pensar, pois a postura crítica exige criarmos formas de acessar o campo produtor daquilo que analisamos para agenciar mudanças de sentidos no próprio processo de produção. 


\section{Adriana Marcondes Machado}

Professora doutora, docente do Instituto de Psicologia da Universidade de São Paulo Email adrimarcon@uol.com.br

\section{Endereço para envio de correspondência:}

Universidade de São Paulo, Instituto de Psicologia, Departamento de Psicologia da Aprendizagem do Desenvolvimento da Personalidade. Av. Prof. Mello Moraes 1721 Bloco A Cidade Universitária. CEP: 05508900. São Paulo - SP. Brasil

Recebido 02/03/2013, 1a Reformulação 07/09/2013, Aprovado 16/10/2013. 
Aguiar, K., \& Rocha, M. (2007). Micropolítica e o exercício da pesquisa-intervenção: referenciais e dispositivos em análise. Psicologia: Ciência e Profissão, 27(4), 648-663. doi: http://dx.doi.org/10.1590/S141498932007000400007

Altoé, S (Org). (2004) René Lourau: Analista Institucional em Tempo Integral. São Paulo: Hucitec.

Chauí, M. (1980). O que é ideologia. São Paulo: Ed. Brasiliense.

Deleuze, G., \& Guattari, F. (2010). O Anti-Édipo. São Paulo: Ed. 34. (Trabalho original publicado em 1972)

Foucault, M. (1987). Theatrum Philosoficum. São Paulo: Mauá.

Foucault, M. (2006). O nascimento da clínica. Rio de Janeiro: Forense Universitária. (Trabalho original publicado em 1980).

Fuganti, L. (2008). Saúde, desejo e pensamento. São Paulo: Linha de Fuga.

Machado, A. M. (2003) Os psicólogos trabalhando com a escola: intervenção a serviço do quê? In: Meira, M.E.; Antunes, M. (Orgs), Psicologia Escolar: práticas críticas. São Paulo: Casa do Psicólogo.
Machado, A. M., Fernandes, A., \& Rocha, M. (Orgs.). (2007). Novos Possíveis no encontro da Psicologia com a Educação. São Paulo: Casa do Psicólogo.

Machado, A. M. \& Souza, M. P. (Orgs.). (1997). Psicologia Escolar: em busca de novos rumos. (5a. ed.). São Paulo: Casa do Psicólogo.

Passos, E., Kastrup, V., \& Escóssia, L. (Orgs.). (2009). Pistas do Método da Cartografia. Porto Alegre: Sulina.

Patto, M. H. S. (1984). Psicologia e Ideologia uma introdução crítica à psicologia escolar. São Paulo: T.A. Queiroz.

Patto, M. H. S. (1990). A Produção do Fracasso Escolar: histórias de submissão e rebeldia. São Paulo: T.A. Queiroz.

Tanamachi, E., Proença, M., \& Rocha, M. (Orgs.). (2000). Psicologia e Educação: desafios teórico-práticos. São Paulo: Casa do Psicólogo. 